\title{
Upregulation of inflammatory genes and downregulation of sclerostin are key elements for fracture healing
}

\author{
J Caetano-Lopes ${ }^{1}$, A Lopes ${ }^{1}$, A Rodrigues ${ }^{1,2}$, D Fernandes ${ }^{1}$, I P Perpétuo ${ }^{1}$, T Monjardino ${ }^{3,4}$, R Lucas L $^{3,4}$, J Monteiro ${ }^{5}$, \\ Y T Konttinen ${ }^{6}$, H Canhão ${ }^{1,2+}$, J E Fonseca ${ }^{1,2^{*}+}$
}

From 5th European Workshop on Immune-Mediated Inflammatory Diseases

Sitges-Barcelona, Spain. 1-3 December 2010

\section{Background}

Fracture healing is orchestrated by a specific set of events that culminates in the repair of bone and reachievement of its biomechanical properties. The aim of our work was to study the sequence of gene expression events involved in inflammation and bone remodeling occurring in the early phases of callus formation in osteoporotic patients.

\section{Methods}

Fifty-six patients submitted to hip replacement surgery after a low-energy hip fracture were enrolled in this study. The patients were stratified according to the time interval between fracture and surgery: bone collected within 3 days after fracture $(n=13)$; between the $4^{\text {th }}$ and $7^{\text {th }}$ day $(n=33)$; and after one week from the fracture $(n=10)$. Inflammation- and bone metabolism-related genes were assessed in trabecular bone.

\section{Results}

The expression of pro-inflammatory cytokines was increased in the first days after fracture. The genes responsible for bone formation and resorption were upregulated one week after fracture. The increase in RANKL expression occurred just before that, between the $4^{\text {th }}-7^{\text {th }}$ days after fracture. Sclerostin expression diminished during the first days after fracture.

\section{Conclusions}

The expression of inflammation-related genes is highest at the very first days after fracture but from day 4 onwards there is a shift towards bone remodeling genes, suggesting that the inflammatory phase triggers bone healing. We propose that an initial inflammatory stimulus and a decrease in sclerostin-related effects are the key components in fracture healing. Local promotion of these two events might constitute a promising medical intervention to accelerate fracture healing.

\section{Author details \\ ${ }^{1}$ Rheumatology Research Unit, Instituto de Medicina Molecular, Faculdade de Medicina da Universidade de Lisboa, Lisbon, Portugal. ${ }^{2}$ Serviço de Reumatologia e Doenças Ósseas Metabólicas, Hospital de Santa Maria, Lisbon, Portugal. ${ }^{3}$ Dept. of Hygiene and Epidemiology, University of Porto Medical School, Porto, Portugal. ${ }^{4}$ Institute of Public Health, University of Porto, Porto, Portugal. ${ }^{5}$ Serviço de Ortopedia, Hospital de Santa Maria, Lisbon, Portugal. ${ }^{6}$ University of Helsinki, Dept. of Medicine; ORTON Orthopaedic Hospital of the Invalid Foundation, Helsinki; COXA Hospital for Joint Replacement, Tampere, Finland.}

Published: 25 November 2010

doi:10.1186/1479-5876-8-S1-P68

Cite this article as: Caetano-Lopes et al: Upregulation of inflammatory genes and downregulation of sclerostin are key elements for fracture healing. Journal of Translational Medicine 2010 8(Suppl 1):P68.

\footnotetext{
† Contributed equally

'Rheumatology Research Unit, Instituto de Medicina Molecular, Faculdade de Medicina da Universidade de Lisboa, Lisbon, Portugal

Full list of author information is available at the end of the article
} 